University of New Orleans

ScholarWorks@UNO

Department of Economics and Finance Working

Papers, 1991-2006

Department of Economics and Finance

1991

\title{
Ownership structure, value of the firm and the bargaining power of the manager
}

Nicholas Mercurio

University of New Orleans

Haralambos Sourbis

Gerald Whitney

University of New Orleans

Follow this and additional works at: https://scholarworks.uno.edu/econ_wp

\section{Recommended Citation}

Mercurio, Nicholas; Sourbis, Haralambos; and Whitney, Gerald, "Ownership structure, value of the firm and the bargaining power of the manager" (1991). Department of Economics and Finance Working Papers, 1991-2006. Paper 55.

https://scholarworks.uno.edu/econ_wp/55

This Article is brought to you for free and open access by the Department of Economics and Finance at ScholarWorks@UNO. It has been accepted for inclusion in Department of Economics and Finance Working Papers, 1991-2006 by an authorized administrator of ScholarWorks@UNO. For more information, please contact scholarworks@uno.edu. 


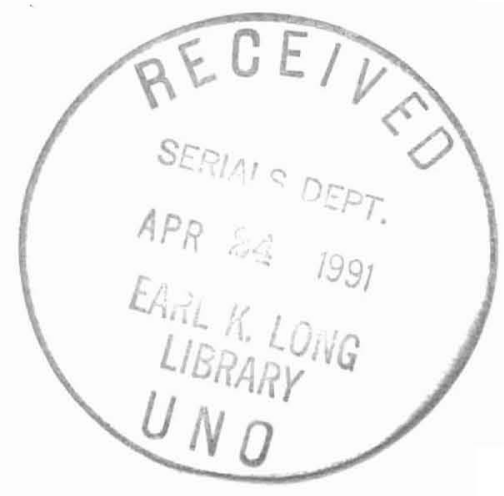

Ownership Structure, Value of the Firm

and the Bargaining Power of the Manager

\author{
Nicholas Mercuro* \\ Haralambos Sourbis \\ and \\ Gerald Whitney*
}

Working Paper \# 1-91

\title{
ECONOMICS AND FINANCE WORKING PAPER SERIES
}
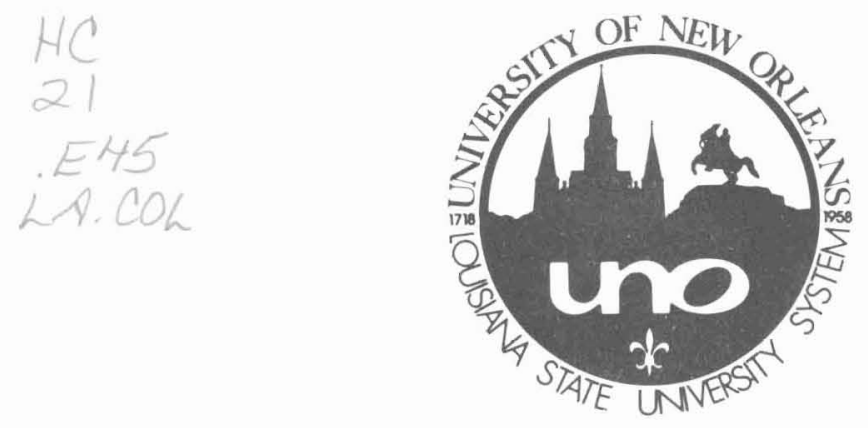

Department of

Economics and Finance

University of New Orleans 
Ownership structure, Value of the Firm and the Bargaining Power of the Manager

\author{
Nicholas Mercuro* \\ Haralambos Sourbis \\ and \\ Gerald Whitney* \\ Working Paper \# 1-91
}

* Professors of Economics, Department of Economics and Finance, University of New Orleans.

For additional copies of this working paper or a current list of the papers available in this series, please contact:

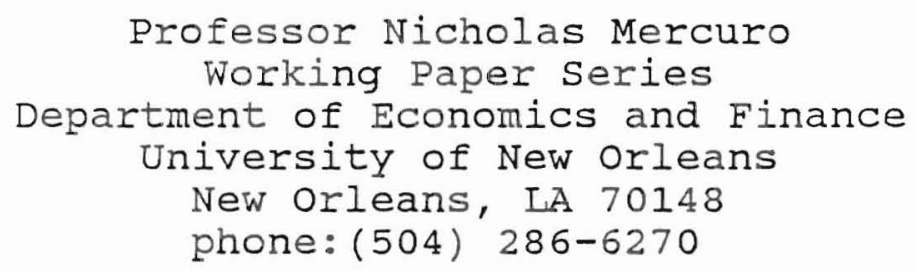

Not for quotation or attribution without permission of authors.

All rights reserved.

COPYRIGHT ○ 1991 


\section{ABSTRACT}

The literature on agency costs has established that the introduction of outside equity results in conflicts between new owners and management that lowers the value of the firm. In contrast, this paper, by focusing on management-labor conflicts, demonstrates that the value of the firm can be increased by the introduction of outside equity. We obtain this result by

showing that the bargaining position of the owner-manager is enhanced when outside equity is increased. As a result, workers with firm-specific skills are persuaded to accept a lower wage, and hence the value of the firm increases. 
OWNERSIIP STRUCTURE, VALUE OF TIE FIRM, AND THE BARGAINING POHER OF THE MANAGER

\section{Introduction}

In their seminal article, Michael Jensen and William Meckling developed a theory of the corporate ownership structure that took into account "the trade-offs available to the entrepreneur-manager between inside and outside equity and debt" (Jensen and Meckling, 1976, p. 312). Jensen and Meckling concentrated on the principal-agent problem and the agency costs that arise from the introduction of outside equity into the firm. This was done without any consideration of what effects such an action might have had on the bargaining power of the owner-manager in negotiating wages with the current employees of the firm.

Several years later Masahiko Aoki (1980; 1984, Chapter 5) introduced a model of the firm that emphasized "its aspect as a quasi-permanent organization of stockholders and employees" (1980, p. 600). He asserted that as a result of the association with the firm, the employees acquire skills and knowledge that, when combined with the physical assets supplied by the stockholders, can produce some economic gains -- the so-called organizational rent. Such rents would not be possible through the employment of external factors of production (such as workers that have no knowledge of the workings of the firm). The organizational rent can be produced only through the cooperation of the stockholders (supplying the physical assets) and the existing employees. As such, the situation is tantamount to a two-person cooperative game, and the question becomes, how then is the organizational rent to be distributed between stockholders and employees. Aoli proposed that the solution to this particular distribution problem could be accomplished by use of a bargaining process attributed to Frederik Zeuthen and John Harsanyi that leads to the Nash bargaining solution. 
Implicit in Aoki's analysis was that all equity was outside equity. Therefore, no attention was given to how alternative ownership structures of the firm affect (1) the bargaining power of the manager and (2) the distribution of the organizational rent. One could start out with an owner-managed firm and examine the distribution of the organizational rent under such an ownership structure. It would then be important to understand how the introduction of outside equity into the firm $\underline{\mathrm{a}} \underline{\text { la }}$ Jensen and Meckling, would affect, if at all, the distribution of the organizational rent.

This paper demonstrates that the introduction of outside equity into a heretofore owner-managed firm increases the bargaining power of a risk averse owner-manager. As a result, the employees' share in the organizational rent will decrease, which will in turn lead to an increase in the value of the firm.

Section II of this paper introduces a simple model of the firm that makes possible the explicit derivation of the organizational rent from the existing market conditions. In addition, Section II sets the stage for the bargaining process that determines the distribution of the organizational rent between stockholders and skilled workers. This process takes the form of negotiations for the determination of a wage rate for skilled workers (and, therefore, the capitalized value of the firm).

The bargaining process itself, and the conditions for reaching an equilibrium, are described in Section III. Thereafter in Section IV, we conclude with an examination of the introduction of outside equity, its effects on the manager's bargaining power and, through that, its effects on the equilibrium of the bargaining process and the value of the firm.

An Appendix contains the more technical derivations and mathematical proofs. 


\section{The Model}

We consider a firm that at period t, given the price per unit of output, $p_{t}$, announced at the end of last period, faces a set of outstanding orders representing a quantity $\bar{q}_{t}$ for its product. The manager must decide on the quantity to produce, $\mathrm{q}\left(\mathrm{q} \leqq \overline{\mathrm{q}}_{\mathrm{t}}\right)$ at the given price. For purposes of simplicity, we assume away the possibility of negative inventories (i.e., backlogging) or positive inventories, so that unfilled orders represent lost sales.1

To introduce the concept of what Aoki (1980) refers to as organizational rent, we assume that, given the existing amount of capital, the employment of outside workers without firm-specific skills and knowledge, at a market wage rate $w_{0}$, enables the firm to fill outstanding orders representing the quantity $q_{0}, q_{0}<\bar{q}_{t}$, of its product. Given a discount rate $r$, let $V^{0}$ represent the capitalized value of the firm under this policy (where $V^{0}>0$ ).

Workers, through their association with the firm for at least one period, acquire firm-specific skills so that their retention by the firm, augmented by the possible addition of unskilled workers, will enable the firm to fill the entire set of outstanding orders, i.e., produce and sell $\bar{q}_{t}$.

Let $C\left(\bar{q}_{t} ; w_{0}\right)$ and $C\left(q_{0} ; w_{0}\right)$ be the costs to the firm for producing quantities $\bar{q}_{t}$ and $q_{0}$, respectively, assuming the skilled and unskilled workers are paid the same wage rate $w_{0}$. Then,

$$
\pi_{t}=\left(\bar{q}_{t}-q_{0}\right) p_{t}-\left[C\left(\bar{q}_{t} ; w_{0}\right)-C\left(q_{0} ; w_{0}\right)\right],
$$

represents the organizational rent that would result from the cooperation of skilled workers with the firm in time period t. It is further assumed that

1 In a bargaining model the possibility of positive or negative inventories may alter the bargaining power of management and labor. This is not considered here. 
$\pi_{t}>0$. The skills of workers with at least one time period's experience with the firm are firm-specific; they cannot be used outside the firm. Therefore, if they seek alternative employment these workers will not be able to earn more than the market wage rate $\mathrm{w}_{0}$. As suggested in the introduction, this implies that the model is equivalent to a two-person cooperative game and the question is how $\pi_{\mathrm{t}}$ will be distributed between skilled workers and the stockholders of the firm.

To explore this question, let us suppose that the part of $\pi_{t}$ going to skilled workers will be determined by the wage rate $w_{t}$ that these workers negotiate at the beginning of each period $t$ with the management of the firm. That is, $w_{t}=w_{0}+u_{t}$ where $u_{t} \geqq 0$ and $u_{t}$ represents that portion of the wage rate received by skilled workers that emanates from the organizational rent. As a consequence, given $w_{0}$ and the discount rate $r$, the capitalized value of the firm can be expressed as a function of $\mathrm{w}_{t}$, with $V\left(\mathrm{w}_{0}\right)$ representing its maximum value, i.e., where the entire organizational rent $\pi_{t}$ goes to the stockholders of the firm.

Alternatively, $V\left(w_{0}+\pi_{t} / N_{t-1}\right)$ represents the firm's minimum value, i.e., when the entire organizational rent $\pi_{t}$ goes to the skilled workers of the firm, that is, the $\mathrm{N}_{\mathrm{t}-1}$ workers employed at period t-1. $\mathrm{V}\left(\mathrm{w}_{t}\right)$ is a linear function of $w_{t}$, with $V^{\prime}\left(w_{t}\right)<0.2$ Therefore the capitalized value of the firm can be represented as in Figure 1.

${ }^{2}$ For given $r$, if the firm receives a fraction $\theta$ of $\pi_{t}$ and slilled workers receive a fraction $(1-\theta)$ of $\pi_{t}$, then $V\left(w_{t}\right)=V\left(w_{0}\right)+\theta \pi_{t} /(1+r)$, and $w_{t}=w_{0}+(1-\theta) \pi_{t} / N_{t-1}$. But $\theta \pi_{t}=\pi_{t}-\left(w_{t}-w_{0}\right) N_{t-1}$. Therefore $V\left(w_{t}\right)=V\left(w_{0}\right)+\left[\pi_{t}-\left(w_{t}-w_{0}\right) N_{t-1}\right](1+r)$ $=V\left(w_{0}\right)+\left[\pi_{t}+w_{0} N_{t-1}\right](1+r)-\left[N_{t-1} /(1+r)\right] w_{t}$. 


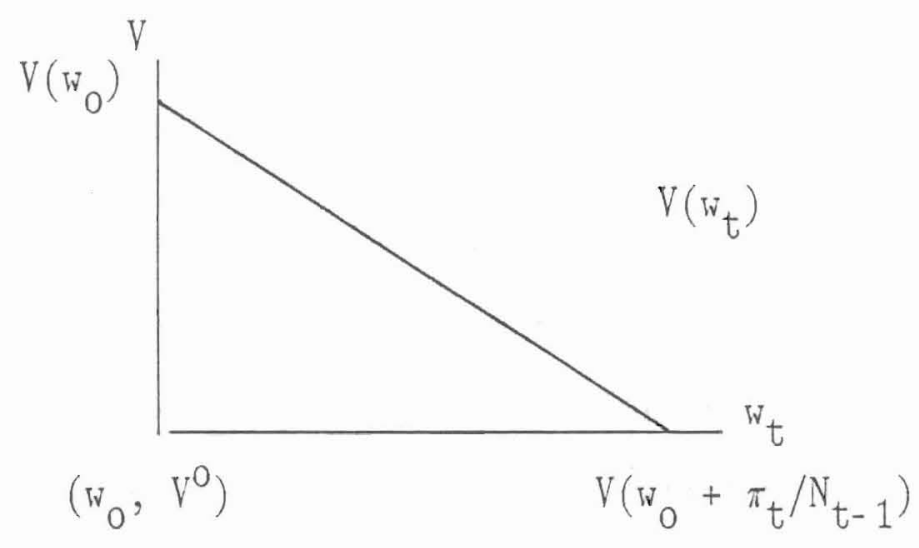

Bargaining Possibilities Frontier

FIGURE 1

The curve $V\left(w_{t}\right)$ represents the "bargaining possibilities frontier" where skilled workers prefer points close to the $\mathrm{w}_{\mathrm{t}}$-axis while stockholders prefer points close to the V-axis.

\section{The Bargaining Process}

In the negotiation process for the determination of the wage rate $w_{t}$ (and, therefore, the value of the firm $V\left(w_{t}\right)$ ), we assume that the "typical" skilled worker is guided by a von Neunann-llorgenstern utility indicator $\mathrm{U}_{\mathrm{L}}$ with wage rate $w_{t}$ as its sole argument, and we assume that $U_{L}^{\prime}\left(w_{t}\right)>0, U_{L}^{\prime \prime}\left(w_{t}\right)<0$.

Likerise, the manager of the firm is guided in the negotiation process by a von Neumann- Horgenstern utility indicator $U_{\mathbb{H}}$ with wealth $\mathbb{N}$ as its sole argument. In particular, we assume that the manager owns a fraction $\alpha, 0<\alpha \leqq 1$ of the firm, and that he holds financial assets in the amount of $W_{F}$ dollars, $W_{F} \geqq 0$. Therefore, for a given wage rate for skilled workers $w_{t}, W=W_{F}+\alpha V\left(w_{t}\right)$, and

$$
U_{\mathrm{UI}}=U_{\mathrm{H}}(\mathrm{W})=\mathrm{U}_{\mathrm{HI}}\left(\mathrm{W}_{\mathrm{F}} \div \mathrm{aV}\left(\mathrm{w}_{\mathrm{t}}\right)\right) \text {. }
$$


Differentiating (2) with respect to ${ }^{t}$ we obtain

$$
\partial \mathrm{U}_{\mathrm{II}} / \partial \mathrm{w}_{\mathrm{t}}=\left(\partial \mathrm{U}_{\mathrm{H}} / \partial \mathrm{W}\right)(\partial \mathrm{W} / \partial \mathrm{V})\left(\partial \mathrm{V} / \partial \mathrm{w}_{\mathrm{t}}\right)=\alpha \mathrm{U}_{\mathrm{II}}^{\prime}(\mathrm{W}) \mathrm{V}^{\prime}\left(\mathrm{w}_{\mathrm{t}}\right) .
$$

Ve assume that $\mathrm{U}_{\mathrm{I}}^{\prime}(\mathrm{W})>0$, $\mathrm{U}_{\mathrm{I}}^{\prime \prime}(\mathrm{W})<0$, and $\mathrm{U}_{\mathrm{II}}^{\prime \prime} \stackrel{\geq}{=}$.

We are now in a position to investigate the bargaining process which can yield a unique $\mathrm{V}$ and $\mathrm{w}$. The process described is largely attributable to Zeuthen. Harsanyi has demonstrated that the Zeuthen solution to the bargaining problem is the Nash bargaining solution. The description of the process closely follows that given by Aoki.

Wages of skilled workers are determined at the beginning of each period by a bargaining process. The parties to the bargaining process are management and a representative skilled employee (Aoki, 1980, p. 604). At the beginning of the period each side must decide to acquiesce or bargain for a concession from the other side. If bargaining is undertaken each side understands that the other side may exercise its threat to withhold cooperation. ${ }^{3}$

The basis for negotiations is a wage rate ${ }^{t} t$ proposed by the manager, where $w_{0} \leqq w_{t}<w_{0}+\pi_{t} / N_{t-1}$. Let $w_{t-1}^{*}$ be the wage rate that skilled workers were paid at period t-1. Then, the wage rate proposed by the manager, $w_{t}$, could be

${ }^{3}$ Harsanyi described the bargaining situation as follows: "Bargaining situations with one possible threat by each party arise either when the two parties can achieve a certain gain by co-operation but when each of them can threaten to withhold his co-operation unless a profit-sharing agreement satisfactory to him is reached, or when one or both parties are able to inflict one particular sort of positive damage on the other party and use the possibility as a threat... But in more general situations the bargaining parties will have a choice among several possible threats, each involving different degrees of non-cooperative or positively damaging behavior. Of course, if there is no obligation to carry out threats in the absence of agreement, the choice among alternative threats may become trivial since each party may then use the most formidable threat against his opponent as a matter of mere bluffing. To exclude this possibility, we may assume that each party is forced to carry out this threat if agreement fails." (Harsanyi, 1956, p. 146) 
less than $w_{t-1}^{*}$. If so, the manager is essentially asking for a concession from the skilled workers. Alternatively he could propose a wage equal to w $_{t-1}$, the wage paid skilled workers in t- 1 .

The skilled workers have two strategies. One consists of (a) accepting the wage rate $w_{t}$ proposed by the manager; the other (b) rejecting $\mathrm{w}_{\mathrm{t}}$ and asking for an increase equal to $\mathrm{h}$. With respect to the latter case, the manager has two strategy options. First, the manager can accept the workers' demand for an increase in $w_{t}$ by $h$, in which case the wage rate of skilled workers for period $t$ will be $w_{t}+h$ and, as a result, the capitalized value of the firm will be $\bar{V}=$ $V\left(w_{t}+h\right)$, where $\bar{V}<V\left(w_{t}\right)=V^{*}$. Alternatively, the manager can reject the workers' demand for an increase in $\mathrm{w}_{\mathrm{t}}$ by $\mathrm{h}$. In this latter case, depending upon the workers' response, there are two possible outcomes. (a) The skilled workers can withdraw their demand. Then, the wage rate remains at $w_{t}$ and the value of the firm is $V\left(w_{t}\right)=V^{*}$; or $(b)$ the skilled workers can insist on their demand resulting in either the worker or management withdrawing their cooperation. In this latter case, the wage rate that skilled workers can earn by seeking alternative employment will be $w_{0}$ and the value of the firm will fall to $V^{0}$, as the firm has to employ unskilled workers.

If skilled workers maximize expected utility, they will enter negotiations, i.e., they will ask for a raise equal to $h$ if their expected gain in utility is greater than their expected loss. More formally

$$
\left(1-p_{1}\right)\left[U_{L}\left(w_{t}+h\right)-U_{L}\left(w_{t}\right)\right]>p_{1}\left[U_{L}\left(w_{t}\right)-U_{L}\left(w_{0}\right)\right]
$$

where $\mathrm{p}_{1}$ is labor's assessment of the probability that management will reject labor's demand and exercise its threat to withhold cooperation thereby resulting 
in a wage of $\mathrm{w}_{0}$. By rearranging terms, it follows that labor will go ahead with its demand for an increase in the wage rate by an increment equal to $h$ if and only if:

$$
p_{1}<\frac{U_{L}\left(w_{t}+h\right)-U_{L}\left(w_{t}\right)}{U_{L}\left(w_{t}+h\right)-U_{L}\left(w_{0}\right)}=p_{1}^{*}\left(w_{t}, h\right)
$$

In $(5), p_{1}^{*}$ represents the maximum risk (maximum probability of conflict) that skilled workers are prepared to face in order to achieve the wage increment $h$.

In a similar manner, the manager will follow the second of the above two strategies, i.e., he will reject the skilled workers' demand for an increase in the wage rate by $h$, if and only if, his expected gain is greater than his expected loss. Hore formally

$$
\begin{gathered}
\left(1-\mathrm{p}_{2}\right)\left[\mathrm{U}_{\mathrm{II}}\left(\alpha \mathrm{V}\left(\mathrm{w}_{\mathrm{t}}\right)+\mathrm{W}_{\mathrm{F}}\right)-\mathrm{U}_{\mathrm{H}}\left(\alpha \mathrm{V}\left(\mathrm{w}_{\mathrm{t}}+\mathrm{h}\right)+\mathrm{W}_{\mathrm{F}}\right)\right]> \\
\mathrm{p}_{2}\left[\mathrm{U}_{\mathrm{II}}\left(\alpha \mathrm{V}\left(\mathrm{w}_{\mathrm{t}}+\mathrm{h}\right)+\mathrm{W}_{\mathrm{F}}\right)-\mathrm{U}_{\mathrm{M}}\left(\alpha \mathrm{V}^{0}+\mathrm{W}_{\mathrm{F}}\right)\right]
\end{gathered}
$$

where $p_{2}$ is the manager's assessment of the probability that skilled workers will insist on their demand after such a demand has been rejected by the manager. Rearranging terms, (6) is equivalent to

$$
\mathrm{p}_{2}<\frac{\mathrm{U}_{\mathrm{MI}}\left(\alpha \mathrm{V}\left(\mathrm{w}_{\mathrm{t}}\right)+\mathrm{w}_{\mathrm{F}}\right)-\mathrm{U}_{\mathrm{II}}\left(\alpha \mathrm{V}\left(\mathrm{w}_{\mathrm{t}}+\mathrm{h}\right)+\mathrm{W}_{\mathrm{F}}\right)}{U_{\mathrm{II}}\left(\alpha \mathrm{V}\left(\mathrm{w}_{\mathrm{t}}\right)+\mathrm{W}_{\mathrm{F}}\right)-\mathrm{U}_{\mathrm{M}}\left(\alpha \mathrm{V}^{0}+\mathrm{w}_{\mathrm{F}}\right)}=\mathrm{p}_{2}^{*}\left(\mathrm{w}_{\mathrm{t}}, \mathrm{h} ; \alpha\right)
$$

In $(7), p_{2}^{*}$ is the maximum risk of conflict that management can tolerate before accepting the workers' demand for an increase in $w_{t}$ by $h$.

Dividing $p_{1}^{*}\left(w_{t}, h\right)$ by $h$, the wage increment, to arrive at the maximum probability per $\mathrm{h}$ of conflict, and letting $\mathrm{h}$ approach zero, we arrive at $\mathrm{LB}_{\mathrm{t}}$, a 
commonly used measure of bargaining porver consistent with Aoli's measure of the employees' bargaining power. LB, at time t:

$$
L B_{t}=\frac{U_{L}^{\prime}\left(w_{t}\right)}{U_{L}\left(w_{t}\right)-U_{L}\left(w_{0}\right)}
$$

In a like manner, dividing $\mathrm{p}_{2}^{*}\left(\mathrm{w}_{\mathrm{t}}, \mathrm{h} ; \alpha\right)$ by $\mathrm{h}$, as $\mathrm{h}$ approaches zero the measure of management's bargaining power, $\mathbb{M B}$, at time $t$ is:

$$
\mathrm{IB}_{t}=-\frac{\alpha U_{\mathrm{II}}^{\prime}\left(\alpha \mathrm{V}\left(\mathrm{w}_{t}\right)+\mathrm{W}_{\mathrm{F}}\right) \mathrm{V}^{\prime}\left(\mathrm{w}_{\mathrm{t}}\right)}{\mathrm{U}_{\mathrm{II}}\left(\alpha \mathrm{V}\left(\mathrm{w}_{\mathrm{t}}\right)+\mathrm{W}_{\mathrm{F}}\right)-\mathrm{U}_{\mathrm{II}}\left(\alpha \mathrm{V}^{0}+\mathrm{W}_{\mathrm{F}}\right)}
$$

Following Zeuthen, we will assume that labor and management have an accurate assessment of each others' resolve to bear the risk of conflict and that each party will make a concession when he finds that his opponent is prepared to bear a greater risk of conflict.4

Under our assumptions regarding strictly concave utility functions, it is clear that $\mathrm{LB}_{t}$ is a decreasing function of $\mathrm{w}_{t}$ while $\mathrm{NB}_{t}$ is an increasing function of $w_{t}$. Graphically the situation is represented as follows:

${ }^{4}$ Zeuthen's behavioral assumption is formally derived in Harsanyi, p. 149-151. 


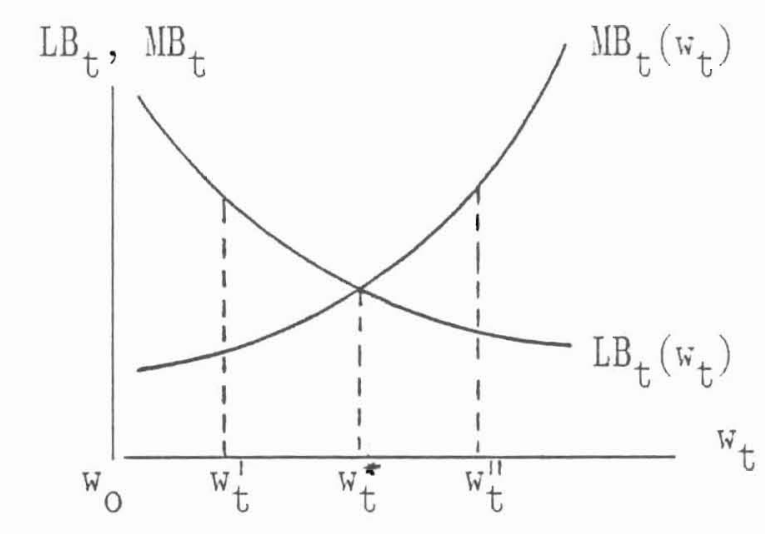

Labor's and Management's Bargaining Power Curves

FIGURE 2

If the manager proposes a wage rate smaller than $w_{t}^{*}$, such as $w_{t}^{1}$ in the above diagram, $L B_{t}\left(w_{t}^{1}\right)>\mathbb{B B}_{t}\left(w_{t}^{1}\right)$ and therefore skilled workers are prepared to bear a greater risk of conflict than management. In this case management concedes to labor's demand for a higher wage rate. In a similar manner if skilled workers reject the manager's proposal and demand a wage rate that is above ${ }^{*}$, such as $w_{t}^{\prime \prime}, \mathbb{B B}_{t}\left(w_{t}^{\prime \prime}\right)>\mathrm{LB}_{t}\left(w_{t}^{\prime \prime}\right)$, then management is prepared to bear a greater risk of conflict than skilled workers. In this case the manager will reject the skilled workers' demand for a higher wage rate. It is only at a wage rate $w_{t}=w_{t}^{*}$ that the resolve of each party to bear risk is equalized, i.e., $\mathbb{I B}_{t}\left(w_{t}^{*}\right)=\mathrm{LB}_{\mathrm{t}}\left(\mathrm{w}_{\mathrm{t}}^{*}\right)$.

We will refer to ${ }^{*}{ }_{t}$ as the equilibrium wage rate of the bargaining process, and it will determine a unique point on the bargaining possibilities frontier together with the respective capitalized value of the firm as established in Figure 1.5

5 As we show in the Appendix [A.1] the equilibrium wage obtained from this process corresponds precisely to the Nash Bargaining Solution. 
IV. Introducing Outside Equity and the Manager's Bargaining Power With a description of the bargaining process in hand, we are now in a position to describe how a sell off of a portion of the firm will affect the equilibrium position on the bargaining possibility frontier. Specifically, we will investigate how $V$ and $w_{t}$ systematically change from a situation where the manager is $100 \%$ owner to a situation where the manager sells off a portion of the firm to outsiders. 6

Without loss of generality we can assume that at the beginning of period $t$ the owner-manager has no financial wealth, only firm-specific wealth, and further he owns $100 \%$ of the firm, i.e., $\alpha=1$. Therefore, any financial wealth that enters his utility function must come from a sale of a portion $\epsilon$, $0<\epsilon<1$, of the firm. With $\alpha$ representing the portion of the firm retained by the manager, $\alpha+\epsilon=1$.

Now, suppose that, faced with a demand by labor for an increase of the wage rate equal to $h$, the owner-manager considers selling a portion $\epsilon$ of his interest in the firm to outsiders, thus, converting interest in the firm to financial assets. This conversion of interest in the firm to financial assets will involve some wealth costs that we assume to be a function of $\epsilon$ and denote by $c(\epsilon)$. We further assume that $c(\epsilon)$ is continuous and twice differentiable for all $\in>0$.

It is intended that the function $c(\epsilon)$ captures all wealth costs that result from the transactions involved in converting interest in the firm to financial assets. In particular, we assume that (a) the owner-manager will be retained in his role as a manager under the new ownership structure of the firm at least for

${ }^{6}$ The conclusions of this section will not be altered if the manager initially owned less than $100 \%$ of the firm. 
the current period, and (b) acting in his own best interests, his managerial tasks will include negotiating a wage rate with the skilled workers. Therefore, in addition to any other costs, such as commissions paid to third parties and income taxes on capital gains, it is intended that the cost function $c(\epsilon)$ captures the agency costs considered by Jensen and Meckling (1976). It will be reasonable, then, to assume that

$$
c(0)=0 ; c(\epsilon)>0, \text { for } \epsilon>0 ; c^{\prime}(\epsilon) \geqq 0 \text { and } c^{\prime \prime}(\epsilon) \geqq 0.7
$$

Let $\hat{V}$ represent the market value of the firm at the beginning of period $t$, (a) before a wage rate for the skilled workers has been determined, and (b) exclusive of any wealth costs that are captured by the cost function $c(\cdot)$. Then, the net receipts from the sale of a portion $\in$ of the firm and, therefore, the manager's financial wealth at period $t$ will be

$$
W_{F}(\epsilon)=\hat{V}-c(\epsilon) \text {. }
$$

An implication of (12) is that, for $0<\epsilon \leqq 1$, the owner-manager's wealth $\mathbb{W}$ can have one of three possible values. If the manager accepts the skilled workers' demand,

$$
\bar{W}(\epsilon)=\alpha V\left(w_{t}+h\right)+\epsilon \hat{V}-c(\epsilon) .
$$

If the manager rejects the skilled workers' demand and the skilled workers withdraw such a demand,

7 According to Jensen and Meckling (1976, p. 313), the wealth costs to the owner-manager will be increasing as his fractional ownership falls. Among the reasons given are: (a) the incentive of the manager to appropriate larger amounts of the corporate resources in the form of perquisites, (b) costs for monitoring his behavior, and (c) his declining incentive to devote significant effort to "creative activities." To these reasons we can add that the owner-manager's decision to sell part of his interest in the firm may signal that there is trouble in the negotiation process with the employees. 


$$
\hat{W}(\epsilon)=\alpha V\left(w_{t}\right)+\epsilon \hat{V}-c(\epsilon) \text {. }
$$

Finally, if the manager rejects the skilled workers' demand and negotiations break down,

$$
W^{0}(\epsilon)=\alpha V^{0}+\epsilon \hat{V}-c(\epsilon) .
$$

Since $\hat{V}$ is independent of the wage rate that will prevail for period $t$, so is $W_{F}$. Therefore, with the proper substitutions of equations (13a), (13b), and (13c) into (6), the derivation of the manager's bargaining power at time $t, \mathbb{N B}_{t}$, in (9) remains valid. However, with (12), $\mathbb{W}_{F}$ was seen to be a function of $\epsilon$. Utilizing (13b) and (13c), we can write

$$
\mathbb{H B}_{t}(\epsilon)=-\frac{\alpha \mathrm{UW}_{\mathrm{H}}^{\prime}(\hat{W}(\epsilon)) \mathrm{V}^{\prime}\left(\mathrm{w}_{\mathrm{t}}\right)}{\mathrm{U}_{\mathrm{H}}(\hat{\mathrm{W}}(\epsilon))-\mathrm{U}_{\mathrm{W}}\left(\mathrm{W}^{0}(\epsilon)\right)}
$$

As a preliminary to the general case, and in order to get an intuitive understanding of the process, let us suppose for a moment that there are no costs involved in selling a portion of the firm by the manager. In particular, let us suppose that $\hat{V}=V\left(w_{t}\right)$. Then, from $(13 b), \hat{W}=V\left(w_{t}\right)$, for any $\epsilon$, and from (13c), $W^{0}=\alpha V^{0}+E V\left(w_{t}\right)$. Substituting into (14) we obtain

$$
\operatorname{IIB}_{t}(\epsilon)=-\frac{\alpha U_{\mathbb{H}}^{\prime}\left(V\left(w_{t}\right)\right) V^{\prime}\left(w_{t}\right)}{U_{\mathbb{I}}\left(V\left(w_{t}\right)\right)-U_{\mathbb{H}}\left(\in V\left(w_{t}\right)+\alpha V^{0}\right)}
$$

On the other hand, for $\alpha=1$, i.e., for $\epsilon=0$,

$$
\mathbb{H B}_{t}(0)=-\frac{U_{M}^{\prime}\left(V\left(w_{t}\right)\right) V^{\prime}\left(w_{t}\right)}{U_{U I}\left(V\left(w_{t}\right)\right)-U_{U}\left(V^{0}\right)}
$$


In comparing the two, the case where $\alpha<1$, with the case where $\alpha=1$, it is easily seen (see Appendix [A.2]) that concavity of the utility function implies that

$$
-\frac{\alpha U_{M}^{\prime}\left(V\left(w_{t}\right)\right) V^{\prime}\left(w_{t}\right)}{U_{H}\left(V\left(w_{t}\right)\right)-U_{I I}\left(\in V\left(w_{t}\right)+\alpha V^{0}\right)}>-\frac{U_{M}^{\prime}\left(V\left(w_{t}\right)\right) V^{\prime}\left(w_{t}\right)}{U_{I I}\left(V\left(w_{t}\right)\right)-U_{I I}\left(V^{0}\right)},
$$

which means that the manager's bargaining power always increases as he substitutes ownership interest in the firm with financial wealth.

With $\hat{V}=V\left(w_{t}\right)$, and $c(\epsilon)=0$, for all $\epsilon$, the manager would have nothing to lose by selling a portion of the firm. In fact, he could always guarantee himself a wealth level equal to $V\left(w_{t}\right)$ with certainty if he were to sell the entire firm. Therefore, with free "insurance" in the event that negotiations break down, together with the assumption that he is retained to negotiate the wage rate in his own best interest, the manager would have nothing to lose by rejecting any demand for an increase in the wage rate. In particular, under the current assumptions of this preliminary case, the manager could impose any wage rate, hovever low, as long as it exceeds the market wage rate $w_{0}$, so that skilled workers would prefer employment with the firm.

Let us proceed now to examine the more realistic case where there are costs involved in selling off a portion of the firm as we have assumed in (11), $c(\epsilon)>0$.

Note that, $\hat{W}(\epsilon)-W^{0}(\epsilon)=\alpha\left(V\left(w_{t}\right)-V^{0}\right)$. Therefore, multiplying both the numerator and the denominator of the right hand side of $(14)$ by $\left(V\left(w_{t}\right)-V^{0}\right)$, setting $U_{\mathbb{H}}^{\prime}(\hat{W}(\epsilon))=b(\epsilon),\left(U_{\mathbb{I I}}(\hat{W}(\epsilon))-U_{\mathbb{I I}}\left(W^{0}(\epsilon)\right)\right) /\left(\hat{W}(\epsilon)-W^{0}(\epsilon)\right)=B(\epsilon)$, and $\left(-V^{1}\left(w_{t}\right) /\left(V\left(w_{t}\right)-V^{0}\right)\right)=A$, we can rewrite (14) as 


$$
\mathrm{IB}_{\mathrm{t}}(\epsilon)=\mathrm{A} \frac{\mathrm{b}(\epsilon)}{\mathrm{B}(\epsilon)},
$$

for any given wage rate $w_{t}$ in the relevant range.

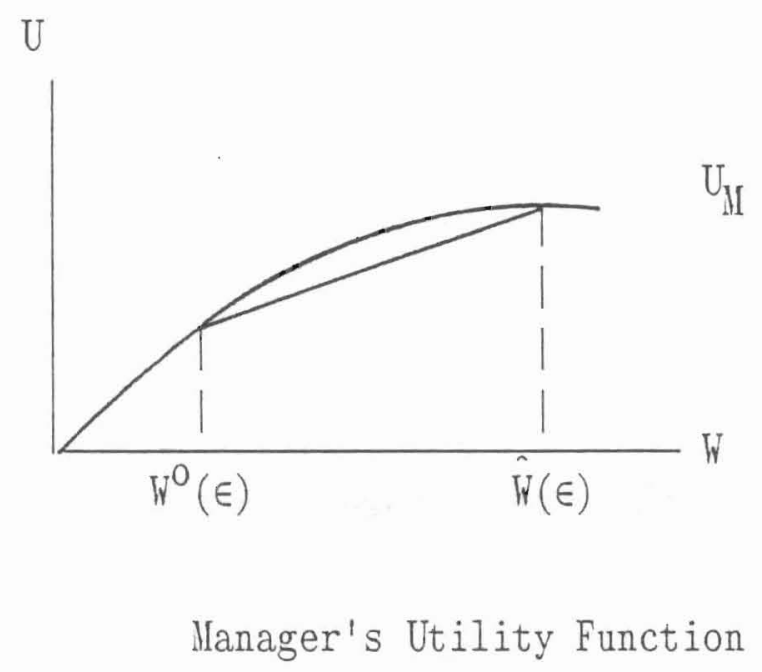

FIGURE 3

In (15), $A$ is independent of $\epsilon$, while, in the graph of the manager's utility function, Figure $3, b(\epsilon)$ represents the slope at the wealth level $\hat{W}(\epsilon)$, and $B(E)$ represents the slope of the straight line joining the two points on the graph corresponding to $\mathrm{W}^{0}(\epsilon)$ and $\hat{W}(\epsilon)$, respectively. Therefore, for any given wage rate $w_{t}$ in the relevant range, the manager's bargaining power is proportional [by a factor $A=-V^{\prime}\left(w_{t}\right) /\left(V\left(w_{t}\right)-V^{0}\right)$ ] to the ratio of the two slopes, $b(\epsilon) / B(\epsilon)$. The slopes $b$ and $B$ represent the manager's feelings concerning changes in wealth. Specifically, b measures the manager's evaluation of small changes in wealth at $\hat{W}(\epsilon)$ while B measures the manager's evaluation of large changes in wealth over the range $\hat{W}$ to $W^{0}$. Recall that the manager's bargaining power is determined by his attitude toward small gains and large losses. 
Now, for a strictly concave utility function, $b(\epsilon)<B(\epsilon)$, for any $\epsilon$ such that $\hat{W}(\epsilon)>W^{0}(\epsilon)$. In particular, if for $\epsilon=0$, we write $V\left(w_{t}\right)=\hat{W}(0)$, and $V^{0}=W^{0}(0)$, then $\hat{W}(0)>W^{0}(0)$, so, if the manager does not sell any portion of the firm, his bargaining power is $\mathrm{A}(\mathrm{b}(0) / \mathrm{B}(0))<\mathrm{A}$. On the other hand as $\epsilon$ tends to 1 , both $\hat{W}(\epsilon)$ and $W^{0}(\epsilon)$ tend to the same certain wealth of $(\hat{V}-c(1))$, which implies that $b(\epsilon)$ tends to $U_{\mathbb{M}}^{\prime}(\hat{V}-c(1))$, and $B(\epsilon)$ tends to $U_{\mathbb{I}}^{\prime}(\hat{V}-c(1))$ [see Appendix (A.3)]. Therefore, as the manager comes closer and closer to selling the entire firm, i.e., as $\in$ tends to $1, b(\epsilon) / B(\epsilon)$ tends to 1 , and $\mathbb{M B}_{t}(\epsilon)$ tends to $\mathrm{A}$.

We have established that as the owner-manager tends to be a pure manager, i.e., as $\in$ tends to 1 , his bargaining power will be greater than in the case where he retains ownership of the entire firm, i.e., for the case where $\epsilon=0$. The question is whether we can obtain a similar result for intermediate cases of $0<\epsilon<1$.

Observe that, for $\epsilon>0$, the wealth functions in (13b) and (13c) are differentiable. Therefore, for $\epsilon>0$,

$$
\begin{aligned}
& \hat{W}^{\prime}(\epsilon)=\frac{\partial \hat{W}}{\partial \epsilon}=\hat{V}-V\left(W_{t}\right)-c^{\prime}(\epsilon) \text {, and } \\
& W^{O}(\epsilon)=\frac{\partial W^{0}}{\partial \epsilon}=\hat{V}-V^{0}-c^{\prime}(\epsilon) .
\end{aligned}
$$

Proposition 1: Assume that either $W^{0^{\prime}}(\epsilon) \geqq-\hat{W}^{\prime}(\epsilon)>0$, or $\hat{H}^{0}(\epsilon)>-\hat{W}^{\prime}(\epsilon) \geqq$ 0 , for all $\epsilon>0$. Then, $\mathbb{B B}_{t}(\epsilon)$ is an increasing function of $\epsilon, \epsilon>0$.

The results of Proposition 1 [see Appendix (A.4) for proof] in conjunction with the previous results that $\mathbb{I B}_{t}(0)<A$ and $\mathbb{I B}_{t}(\epsilon)$ tends to $A$ as $\in$ tends to 1 , are sufficient to establish proposition 2 . 
Proposition 2. Assume that either $\mathrm{W}^{0}(\epsilon) \geqq-\hat{W}^{\prime}(\epsilon)>0$, or $\mathrm{W}^{0}(\epsilon)>-\hat{W}^{\prime}(\epsilon) \geqq$ 0 , for all $\epsilon>0$. Then there exists an $\bar{\epsilon}, 0 \leqq \bar{\epsilon}<1$, such that $\operatorname{IB}_{t}(\epsilon)>\operatorname{IB}_{t}(0)$, for all $\epsilon>\bar{\epsilon}$.

This establishes that a sufficiently large sell-off by the manager will increase his bargaining power. Sufficient conditions for this result are that: (a) the sell-off increases wealth in the event of a breakdown in negotiations and reduces or leaves wealth unchanged when negotiations are successful; and (b) the gain in wealth under a breakdown in negotiations exceeds the loss in wealth when negotiations are successful.

This condition may be interpreted (as in the preliminary case where costs were assumed to be zero) as a form of insurance in the event that negotiations break down. The "cost of insurance" in the present case would be $-\hat{\mathbb{F}}^{\prime}(\epsilon)$, the reduction in wealth of the manager under the best-case outcome when labor concedes. The protection he receives, in the event that negotiations break down is $\mathrm{W}^{0}(\epsilon)$. Hence, our results here are similar to those when we assumed no costs. The bargaining power of the manager increases as long as the protection he receives in the event of a strike exceeds the cost of his "insurance."

Unless $\bar{E}=0$ in Proposition 2, a sell-off of a small portion of the firm, $\epsilon<\bar{\epsilon}$ may lower the manager's bargaining power. The reason is the presence of lump-sum costs. Suppose for a moment that lump-sum costs of $\bar{c}$ are incurred when the manager sells part of his equity. Then from (12), as $\in$ approaches 0 , the proceeds from the sale approach 0 while costs approach $\bar{c}$. Hence, regardless of the outcome of negotiations, the manager's wealth is less than it would have been under no sale of equity. As a consequence, even though by Proposition 1, 
the manager's bargaining power is an increasing function of $\epsilon$, for $\epsilon>0$, there may be a range of $\epsilon$ such that $\mathbb{N B}_{t}(\epsilon)$ stays below $\mathbb{N B}_{t}(0)$. This occurs because the manager's wealth is now lower due to the lump-sum cost $\bar{c} .8$ Clearly since lump sum costs lower the manager's bargaining power only when a sell-off makes the manager unambiguously worst off, it is safe to assume that such an outcome would be unlikely.

In the absence of lump-sum costs $\mathbb{I B}_{t}(\epsilon)>\mathbb{B}(0)$. Nore formally the following proposition is valid.

Proposition 3. Assume that (a) there are no lump-sum costs and (b) either $\mathrm{W}^{0^{\prime}}(\epsilon) \geqq \hat{W}^{\prime}(\epsilon)>0$ or $\mathrm{W}^{0}(\epsilon)>-\hat{W}^{\prime}(\epsilon) \geqq 0$ for all $\epsilon>0$. Then $\mathbb{U B}_{t}(\epsilon)>\mathbb{I B}_{\mathrm{t}}(0)$, for all $\epsilon>0$.

In conjunction with Proposition 1, Proposition 3 implies that the manager's bargaining power increases as he sells a larger share of the firm and is always larger than when he retains full ownership.

Let's now turn our attention to the effects of a sell-off on the value of the firm. The propositions above establish that under general conditions a sell-off of the firm will, for any given wage rate, increase the manager's bargaining power. This means that a sell-off will shift the $\mathrm{MB}_{\mathrm{t}}$ curve (initially presented in Figure 2) towards the northwest as depicted in Figure 4.

8. Wathematically the function $\mathbb{N B}_{\mathrm{t}}(\epsilon)$ is not differentiable at $\epsilon=0$ if $\overline{\mathrm{c}}>0$. 


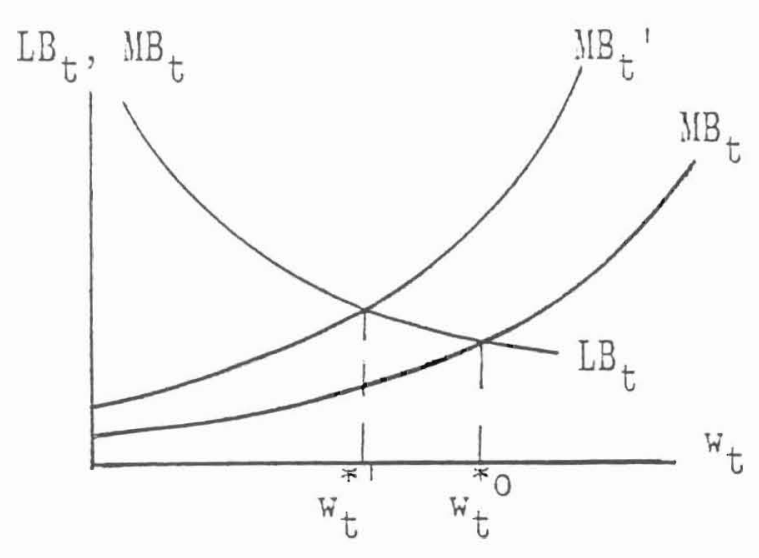

FIGURE 4

Recall from Section III, that the equilibrium wage is established at the wage which equalizes the manager's and labor's bargaining porer. Hence the sell-off which shifts the $\mathbb{M B}_{t}$ curve northwest to $\mathbb{I B}_{t}^{\prime}$, results in a lowered equilibrium wage of $\boldsymbol{w}_{t}{ }^{*}$. Stockholders now capture a larger portion of the organizational rent, and as a result the value of the firm increases.

\section{Conclusions}

In this paper we have demonstrated that the introduction of outside equity in an owner-managed firm can increase its value. The introduction of outside equity, even at a cost, serves as insurance for the manager in the event that negotiations break down. Since he no longer bears the entire cost, the owner-manager is more willing to risk a breakdown in negotiations to achieve wage concessions from skilled labor. Labor perceives this, and accepts a lower wage.

Our assumptions preclude the possibility that the new stockholders are the current employees of the firm. An interesting extension would be to examine how the results reported here are altered if labor purchases a portion of the firm. 


\section{Appendix}

[A.1] To establish that the equilibrium wage rate ${ }^{*}{ }_{t}$ obtained by setting $M B_{t}=L B_{t}$, is the same as that obtained from the Nash bargaining solution, consider the first order condition for the maximization of the product $\left(\mathrm{U}_{\mathrm{H}}\left(\alpha \mathrm{V}\left(\mathrm{w}_{t}\right)+\mathrm{w}_{\mathrm{F}}\right)-\mathrm{U}_{\mathrm{H}}\left(\alpha \mathrm{V}^{0}+\mathrm{w}_{\mathrm{F}}\right)\right) \cdot\left(\mathrm{U}_{\mathrm{L}}\left(\mathrm{w}_{t}\right)-\mathrm{U}_{\mathrm{L}}\left(\mathrm{w}_{0}\right)\right)$ with respect to $\mathrm{w}_{t} \cdot$ Differentiating this product with respect to $\mathrm{w}_{t}$ and setting it equal to 0 we obtain: $U_{\mathrm{II}}^{\prime}\left(\alpha \mathrm{V}\left(\mathrm{w}_{\mathrm{t}}\right)+\mathrm{w}_{\mathrm{F}}\right)\left(\alpha \mathrm{V}^{\prime}\left(\mathrm{w}_{\mathrm{t}}\right)\right)\left(\mathrm{U}_{\mathrm{L}}\left(\mathrm{w}_{\mathrm{t}}\right)-\mathrm{U}_{\mathrm{L}}\left(\mathrm{w}_{0}\right)\right)+\left(\mathrm{U}_{\mathrm{II}}\left(\alpha \mathrm{V}\left(\mathrm{w}_{\mathrm{t}}\right)+\mathrm{W}_{\mathrm{F}}\right)-\mathrm{U}_{\mathrm{II}}\left(\alpha \mathrm{V}^{0}+\right.\right.$ $\left.\left.\mathrm{W}_{\mathrm{F}}\right)\right) \cdot \mathrm{U}_{\mathrm{L}}^{\prime}\left(\mathrm{w}_{\mathrm{t}}\right)=0$. So, at the $\mathrm{w}_{\mathrm{t}}^{*}$ that solves this equation,

$$
\frac{U_{L}^{\prime}\left(w_{t}^{*}\right)}{U_{L}\left(w_{t}^{*}\right)-U_{L}\left(w_{0}\right)}=-\frac{\alpha U_{I}^{\prime}\left(\alpha V\left(w_{t}^{*}\right)+w_{F}\right) V^{\prime}\left(w_{t}^{*}\right)}{U_{I I}\left(\alpha V\left(w_{t}^{*}\right)+w_{F}\right)-U_{I I}\left(\alpha V^{0}+w_{F}\right)} \text {. }
$$

[A.2] To prove that

$$
-\frac{\alpha U_{I}^{\prime}\left(V\left(w_{t}\right)\right) V^{\prime}\left(w_{t}\right)}{U_{I I}\left(V\left(w_{t}\right)\right)-U_{I I}\left(\in V\left(w_{t}\right)+\alpha V^{0}\right)}>-\frac{U_{I}^{\prime}\left(V\left(w_{t}\right)\right) V^{\prime}\left(w_{t}\right)}{U_{I I}\left(V\left(w_{t}\right)\right)-U_{I I}\left(V^{0}\right)}
$$

multiply the nominator and denominator of the fraction on the right-hand side of this inequality by $\alpha$. This will equalize the nominators of the two fractions and will make the denominator of the second equal to $\alpha\left(U_{\mathbb{M}}\left(V_{(}\left(w_{t}\right)\right)-U_{M}\left(V^{0}\right)\right)$. Note that by the strict concavity of $U_{\mathbb{H}}, U_{\mathbb{I}}\left(\in V\left(w_{t}\right)+\alpha V^{0}\right)>\in U_{\mathbb{I I}}\left(V\left(w_{t}\right)\right)+$ $\alpha \mathrm{U}_{\mathrm{HI}}\left(\mathrm{V}^{0}\right)$. Since $\epsilon=1-\alpha, \mathrm{U}_{\mathrm{II}}\left(\in \mathrm{V}\left(\mathrm{w}_{\mathrm{t}}\right)+\alpha \mathrm{V}^{0}\right)>\mathrm{U}_{\mathrm{II}}\left(\mathrm{V}\left(\mathrm{w}_{\mathrm{t}}\right)\right)-\alpha\left(\mathrm{U}_{\mathrm{II}}\left(\mathrm{V}\left(\mathrm{w}_{\mathrm{t}}\right)\right)-\mathrm{U}_{\mathrm{HI}}\left(\mathrm{V}^{0}\right)\right)$, which implies that $\alpha\left(U_{\mathbb{I I}}\left(V\left(w_{t}\right)\right)-U_{M}\left(V^{0}\right)>U_{M I}\left(V\left(w_{t}\right)\right)-U_{M I}\left(\in V\left(w_{t}\right)+\alpha V^{0}\right)\right.$, which completes the proof.

[A.3] To show that, as $\epsilon \rightarrow 1,(b(\epsilon) / B(\epsilon)) \rightarrow 1$, observe that, as $\epsilon \rightarrow 1$, both the nominator and the denominator of $B(\epsilon)$ tend to 0 , so that $B(\epsilon)$ tends to the indeterminate form $(0 / 0)$. However, 


$$
\begin{aligned}
& \operatorname{limit}\left(U_{\mathbb{H}}^{\prime}(\hat{W}(\epsilon)) \hat{W}^{\prime}(\epsilon)-U_{\mathbb{H}}^{\prime}\left(W^{0}(\epsilon)\right) W^{01}(\epsilon)\right)=U_{\mathbb{H}}^{\prime}(\hat{V}-c(1))\left(\hat{W}^{\prime}(1)-W^{0}(1)\right) \\
& \epsilon \rightarrow 1
\end{aligned}
$$

while

$$
\operatorname{limit}_{\epsilon \rightarrow 1}\left(\hat{W}^{\prime}(\epsilon)-W^{0}(\epsilon)\right)=\left(\hat{W}^{\prime}(1)-W^{0}(1)\right) .
$$

But from $(16)$ and $(17),\left(\hat{W}^{\prime}(\epsilon)-W^{0}(\epsilon)\right)=-\left(V\left(w_{t}\right)-V^{0}\right) \neq 0$, for all $\epsilon>0$. Therefore,

$$
\operatorname{limit}_{\epsilon \rightarrow 1} \frac{U_{M}^{\prime}(\hat{W}(\epsilon)) \hat{W}^{\prime}(\epsilon)-U_{W}^{\prime}\left(W^{0}(\epsilon)\right) W^{0}(\epsilon)}{\hat{W}^{\prime}(\epsilon)-W^{0}(\epsilon)}=U_{W}^{\prime}(\hat{V}-c(1)) .
$$

By L'Hospital's rule about indeterminate forms $(0 / 0)$,

$$
\operatorname{limit}_{\epsilon \rightarrow 1} B(\epsilon)=U_{I I}^{\prime}(\hat{\mathrm{V}}-c(1))=b(1) \text {. }
$$

[A.4] To prove that under the conditions of Proposition 1, the function $\mathbb{M B}_{\mathrm{t}}(\epsilon)$ is an increasing function of $\epsilon$, note that for $\epsilon>0$, both functions $b(\epsilon)$ and $B(\epsilon)$ are differentiable. Therefore, differentiating (15) with respect to $\epsilon$ we obtain

$$
\operatorname{IIB} B_{t}^{\prime}(\epsilon)=A \frac{b^{\prime}(\epsilon) B(\epsilon)-b(\epsilon) B^{\prime}(\epsilon)}{(B(\epsilon))^{2}}
$$

where primes denote first derivatives of the respective functions. Note that $A>0$, and $B(\epsilon)>0$, so, sign $\left(\operatorname{MB}_{t}^{\prime}(\epsilon)\right)=\operatorname{sign}\left(b^{\prime}(\epsilon) B(\epsilon)-b(\epsilon) B^{\prime}(\epsilon)\right)$.

By definition, $b(\epsilon)=U_{\mathbb{I}}^{\prime}(\hat{W}(\epsilon))$, and this implies that $b^{\prime}(\epsilon)=U_{\mathbb{M}}^{\prime \prime}(\hat{W}(\epsilon)) \hat{W}^{\prime}(\epsilon)$ where, by assumption, $U^{\prime \prime}(\hat{W}(\epsilon))<0$. Therefore, $b^{\prime}(\epsilon)>0$ if $\hat{W}^{\prime}(\epsilon)<0$, and $b^{\prime}(\epsilon)=0$ if $\hat{W}^{\prime}(\epsilon)=0$. Also by definition, $\left.B(\epsilon)=U_{\mathbb{W}}(\hat{W}(\epsilon))-U_{M}\left(W^{0}(\epsilon)\right)\right) /(\hat{W}(\epsilon)$ 
- $\left.\mathbb{H}^{0}(\epsilon)\right)>0($ see $[A .3])$. Since $\hat{W}^{\prime}(\epsilon) \leqq 0$, it follows that $b^{\prime}(\epsilon) B(\epsilon)>0$ if $\hat{W}^{\prime}(\epsilon)<0$, and $b^{\prime}(\epsilon) B(\epsilon)=0$ if $\hat{W}^{\prime}(\epsilon)=0$. As a consequence, (a) if $\hat{W}^{\prime}(\epsilon)<0$, then, $\mathbb{H B}_{\mathrm{t}}^{\prime}(\epsilon)>0$ provided that $-\mathrm{b}(\epsilon) \mathrm{B}^{\prime}(\epsilon) \geqq 0$, and $(\mathrm{b})$ if $\hat{W}^{\prime}(\epsilon)=0$, then $\mathbb{M B}_{\mathrm{t}}^{\prime}(\epsilon)$ $>0$ provided that $-\mathrm{b}(\epsilon) \mathrm{B}^{\prime}(\epsilon)>0$.

Differentiate $B(\epsilon)$ with respect to $\epsilon$ to obtain

$B^{\prime}(\epsilon)=$

$\left.U_{\mathbb{I I}}^{\prime}(\hat{W}(\epsilon)) \hat{W}^{\prime}(\epsilon)-U_{\mathbb{I I}}^{\prime}\left(W^{0}(\epsilon)\right) W^{0}(\epsilon)\right)\left(\hat{W}(\epsilon)-W^{0}(\epsilon)\right)-\left(U_{M}(\hat{W}(\epsilon))-U_{M}\left(W^{0}(\epsilon)\right)\right)\left(\hat{W}^{\prime}(\epsilon)-W^{0}(\epsilon)\right)$

$$
\left.\hat{W}(\epsilon)-W^{0}(\epsilon)\right)^{2}
$$

Factoring out the term $\left.\left(\hat{W}^{\prime}(\epsilon)-W^{0}(\epsilon)\right) / \hat{W}(\epsilon)-\hat{W}^{0}(\epsilon)\right)$, and making use of the definition of $\mathrm{B}(\epsilon)$, $\mathrm{B}^{\prime}(\epsilon)$ can be written as

$$
\mathrm{B}^{\prime}(\epsilon)=\frac{\hat{W}^{\prime}(\epsilon)-\mathrm{W}^{0^{\prime}}(\epsilon)}{\hat{W}(\epsilon)-W^{0}(\epsilon)}\left[\frac{U_{\mathrm{WI}}^{\prime}(\hat{W}(\epsilon)) \hat{W}^{\prime}(\epsilon)-U_{\mathrm{H}}^{\prime}\left(\mathrm{WP}^{0}(\epsilon)\right) \mathrm{W}^{0^{\prime}}(\epsilon)}{\hat{W}^{\prime}(\epsilon)-\mathrm{W}^{0}(\epsilon)}-B(\epsilon)\right]
$$

From $(16)$ and $(17),\left(\hat{W}^{1}(\epsilon)-W^{0}(\epsilon)\right)=-\left(V\left(w_{t}\right)-V^{0}\right)$, a negative number, while from the conditions of Proposition $1, \hat{W}^{\prime}(\epsilon) \leqq 0$, and $\mathbb{W}^{0}(\epsilon)>0$.

Define $\delta(\epsilon)=-W^{0}(\epsilon) /\left(\hat{W}^{\prime}(\epsilon)-W^{0}(\epsilon)\right)$, so $(1-\delta(\epsilon))=\hat{W}^{\prime}(\epsilon) /\left(\hat{W}^{\prime}(\epsilon)-\right.$ $\left.W^{0}(\epsilon)\right)$. Then, $1 / 2 \leqq \delta(\epsilon) \leqq 1$, for each $\epsilon$. In particular, if $\hat{W}^{\prime}(\epsilon)=0, \delta(\epsilon)=$ 1 , while if $\hat{W}^{\prime}(\epsilon)<0, \delta(\epsilon) \geqq 1 / 2$ (which follows from the conditions of Proposition 1). Substituting $\delta(\epsilon)$ and $1-\delta(\epsilon)$ for the corresponding terms in $B^{\prime}(\epsilon)$ yields

$$
\mathrm{B}^{\prime}(\epsilon)=\frac{\hat{W}^{\prime}(\epsilon)-W^{0}(\epsilon)}{\hat{W}(\epsilon)-W^{0}(\epsilon)}\left((1-\delta(\epsilon)) \mathrm{U}_{\mathbb{H}}^{\prime}(\hat{W}(\epsilon))+\delta(\epsilon) \mathrm{U}_{\mathbb{H}}^{\prime}\left(W^{0}(\epsilon)\right)-B(\epsilon)\right) \text {. }
$$

Now $U_{\mathbb{I}}^{\prime}(W)$ is a convex function (i.e., $U_{\mathbb{H}}^{\prime \prime}(W)<0$, and $U_{\mathbb{H}}^{\prime \prime}{ }^{\prime}(W) \geqq 0$ ). Therefore 


$$
\begin{aligned}
& \quad\left[\mathrm{U}_{\mathbb{H}}^{\prime}(\hat{W}(\epsilon))+1 / 2\left(\mathrm{U}_{\mathbb{H}}^{\prime}\left(\mathrm{WH}^{0}(\epsilon)\right)-\mathrm{U}_{\mathbb{H}}^{\prime}(\hat{W}(\epsilon))\right)\right]\left(\hat{W}(\epsilon)-\mathrm{H}^{0}(\epsilon)\right) \geqq\left(\mathrm{U}_{\mathbb{H}}(\hat{W}(\epsilon))-\right. \\
& \left.\mathrm{U}_{\mathbb{H}}\left(W^{0}(\epsilon)\right)\right) .
\end{aligned}
$$

That is, the area under the straight line that connects any two different points on the graph of $U_{\mathbb{I}}^{\prime}(W)$ is at least as great as the area under the graph between those points.

Dividing both sides of the above inequality by $\left(\hat{W}(\epsilon)-\mathbb{W}^{0}(\epsilon)\right)$, a positive number for $\epsilon<1$, we obtain

$$
\left.U_{\mathbb{W}}^{1}(\hat{W}(\epsilon))+1 / 2\left(U_{\mathbb{W}}^{\prime}\left(W^{0}(\epsilon)\right)-U_{\mathbb{H}}^{\prime}(\epsilon)\right)\right) \geqq \frac{U_{\mathbb{I S}}\left(\hat{W}(\epsilon)-U_{\mathbb{M I}}\left(W^{0}(\epsilon)\right)\right.}{\hat{W}(\epsilon)-W^{0}(\epsilon)}=B(\epsilon) .
$$

However,

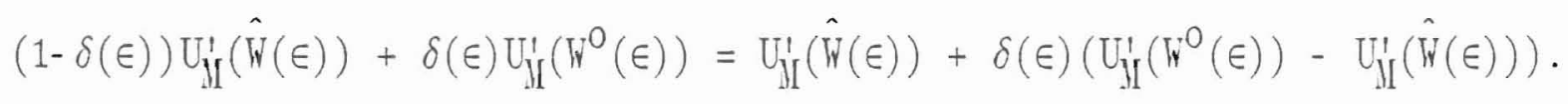

Therefore, if $\hat{W}^{\prime}(\epsilon)<0, \delta(\epsilon) \geqq 1 / 2$, and

$$
\mathrm{U}_{\mathbb{W}}^{\prime}(\hat{W}(\epsilon))+\delta(\epsilon)\left(\mathrm{UW}_{\mathbb{W}}^{\prime}\left(W^{0}(\epsilon)\right)-U_{\mathbb{W}}^{\prime}(\hat{W}(\epsilon)) \geqq B(\epsilon),\right.
$$

which implies that $\mathrm{B}^{\prime}(\epsilon) \leqq 0$, while, if $\hat{\mathrm{W}}^{\prime}(\epsilon)=0, \delta(\epsilon)=1$, and

$$
\mathrm{U}_{\mathbb{W}}^{\prime}(\hat{W}(\epsilon))+\delta(\epsilon)\left(\mathrm{U}_{\mathbb{W}}^{\prime}\left(\mathrm{WW}^{0}(\epsilon)\right)-\mathrm{U}_{\mathbb{M}}^{\prime}(\hat{W}(\epsilon))>\mathrm{B}(\epsilon),\right.
$$

which implies that $\mathrm{B}^{\prime}(\epsilon)<0$. With $\mathrm{b}(\epsilon)=\mathrm{U}_{\mathrm{X}}^{\prime}(\hat{\mathrm{W}}(\epsilon))>0$, it follows that $-\mathrm{b}(\epsilon) \mathrm{B}^{\prime}(\epsilon) \geqq 0$ if $\hat{W}^{\prime}(\epsilon)<0$, and $-\mathrm{b}(\epsilon) \mathrm{B}^{\prime}(\epsilon)>0$ if $\hat{H}^{\prime}(\epsilon)=0$, which completes the proof. 


\section{References}

Aoki, M., "A Model of the Firm as a Stockholder-Employee Cooperative Game," American Economic Review, Vol. 70, No. 4, (September 1980), pp. 600-610.

Aoki, M., The Co-Operative Game Theorv of the Firm (New York: Oxford University Press, 1984).

Harsanyi, J.C., "Approaches to the Bargaining Problem Before and After the Theory of Games: A Critical Discussion of Zeuthen's, Hicks', and Nash's Theories," Econometrica, Vol. 24, No. 2 (April 1956), pp. 144-157.

Jensen, M.C., and Meckling, W.H., "Theory of the Firm: Managerial Behavior, Agency Costs and Ownership Structure," Journal of Financial Economics, Vol. 3 (1976), pp. 305-360.

Zeuthen, F., Problems of Monopoly and Economic Warfare (New York: Agustus II. Kelly Publishers, 1968). 